\title{
Phlebitis, CTCAE
}

National Cancer Institute

\section{Source}

National Cancer Institute. Phlebitis, CT CAE. NCI Thesaurus. Code C143761.

A disorder characterized by inflammation of the wall of a vein. 